\title{
Do fund managers perceive environmental information useful? An empirical study from Malaysia
}

\begin{abstract}
Pressure for companies to be accountable to stakeholders has encouraged companies to report information on employees, products and the environment. However, it costs companies time, energy and money. Consequently, such information should be of value to corporate preparers and stakeholders. Accordingly, the primary objective of the study is to examine the importance of environmental information in the decisions of fund managers. The normative pressure of institutional theory was used to explain the findings. More specifically, we argue that the emphasis of companies' bottom line in the education and professional training received by fund managers may influence their perception on the usefulness of environmental information in their decision to invest. The survey method was used to collect the data. The results reveal that fund managers rated many environmental items as important. Additionally, environmental information is viewed as important to be disclosed when it affects the company's future financial performance and this, in turn, will influence stakeholders' decisions. More importantly, fund managers believe that environmental information disclosure should be mandatory for all companies in Malaysia. Despite the lack of emphasis on social and environmental issues on the education and professional training of fund managers, the results revealed that they still perceive environmental information to be useful. Accordingly, the normative isomorphism of institutional theory is not supported.
\end{abstract}

Keyword: Environmental information; Perception; Fund manager; Malaysia 